\title{
CAPACIDADE LIMITADA DE INDUÇÃO FEDERAL NA IMPLEMENTAÇÃO DO PROGRAMA ESPORTE E LAZER DA CIDADE - PELC
}

\author{
Recebido em: 06/03/2021 \\ Aprovado em: $24 / 08 / 2021$
}

Licença:@() @ @

\author{
Luciana Assis Costa ${ }^{1}$ \\ Luciano Pereira da Silva ${ }^{2}$ \\ Daniete Fernandes Rocha ${ }^{3}$ \\ Natascha Stephanie Nunes Abade \\ Brisa de Assis Pereira \\ Marcus Peixoto de Oliveira ${ }^{6}$ \\ Universidade Federal de Minas Gerais (UFMG) \\ Belo Horizonte $-\mathrm{MG}-$ Brasil
}

RESUMO: O PELC é um programa nacional de esporte e lazer, criado em 2003, coordenado pelo governo federal e implementado no âmbito municipal. Analisar a implementação dos convênios do PELC no período de 2013 a 2017, com foco nas possibilidades de continuidade do programa na esfera municipal. Trata-se de um estudo qualitativo, de natureza estudo de caso associado a um estudo quantitativo observacional descritivo. A análise abrangeu o total de 43 municípios que implementaram o PELC. Os dados apontam que o potencial de indução para continuidade do Programa é pequeno, tendo em vista que a maioria dos municípios $\mid$ pretende realizar novo convênio para continuidade do projeto. A capilaridade do PELC $\mid$

\footnotetext{
1 Doutora em Sociologia pela Universidade Federal de Minas Gerais, Professora Associada do Departamento de Terapia Ocupacional e Docente Permanente do Programa de Pós-Graduação em Estudos do Lazer - EEFFTO/UFMG e do Programa de Mestrado em Estudos da Ocupação EEFFTO/UFMG. Coordenadora do Núcleo de Estudos de Exclusão e Políticas Sociais - NEOPolis.

${ }^{2}$ Doutor em Educação pela Universidade Federal de Minas Gerais, Professor Adjunto do Departamento de Educação Física EEFFTO/UFMG e Diretor do Centro Esportivo Universitário CEU/UFMG. Coordenador do Grupo de Estudo e Pesquisa em Políticas Públicas de Esporte e Lazer POLIS/UFMG.

${ }^{3}$ Doutora em Ciências Humanas: Sociologia e Política, pela Universidade Federal de Minas Gerais. Docente na Faculdades Arnaldo Janssen. Grupo de Estudos Observatório de Política Social e Núcleo de Estudos de Exclusão e Políticas Sociais - NEOPolis.

${ }^{4}$ Doutoranda e Mestre pelo Programa de Pós-Graduação Interdisciplinar em Estudos do Lazer (PPGIEL) da Universidade Federal de Minas Gerais (UFMG). Bacharel em Educação Física pela UFMG. Licenciada em Educação Física pelo Centro Universitário Claretiano. Grupo de Estudo e Pesquisa em Políticas Públicas de Esporte e Lazer POLIS/UFMG.

${ }^{5}$ Doutoranda e Mestra pelo Programa de Pós-Graduação Interdisciplinar em Estudos do Lazer (PPGIEL) da Universidade Federal de Minas Gerais (UFMG). Bolsista da Coordenação de Aperfeiçoamento de Pessoal de Nível Superior - Brasil (CAPES). Bacharel em Educação Física pela UFMG. Licenciada em Educação Física pelo Centro Universitário Claretiano. Grupo de Estudo e Pesquisa em Políticas Públicas de Esporte e Lazer POLIS/UFMG.

6 Mestre pelo Programa de Pós-Graduação Interdisciplinar em Estudos do Lazer (PPGIEL) da Universidade Federal de Minas Gerais (UFMG). Bacharelado em Educação Física pela Universidade Federal do Rio de Janeiro. Especialização em Ciência da Performance Humana pela Universidade Federal do Rio de Janeiro. MBA em Gestão e Marketing Esportivo pela Trevisan. Grupo de Estudo e Pesquisa em Políticas Públicas de Esporte e Lazer POLIS/UFMG.
} 
ainda é baixa, bem como a sua cobertura, além de não atender a equidade regional, dada a concentração de municípios conveniados na região sudeste.

PALAVRAS-CHAVE: Políticas de Esporte e Lazer. Coordenação Intergovernamental.

Capacidade Estatal.

\section{LIMITED FEDERAL INDUCTION CAPACITY IN IMPLEMENTING THE CITY SPORT AND LEISURE PROGRAM - PELC}

ABSTRACT: PELC is a national sports and leisure program, created in 2003, coordinated by the federal government and implemented at the municipal level. Analyze the implementation of the PELC agreements in the period from 2013 to 2017, focusing on the possibilities of continuity of the program at the municipal level. It is a qualitative study, of a case study nature associated with a descriptive observational quantitative study. The analysis covered a total of 43 municipalities that implemented the PELC. The data show that the potential for inducing continuity of the Program is small, considering that most municipalities intend to make a new agreement for the continuity of the project. The capillarity of the PELC is still low, as well as its coverage, in addition to not attending to regional equity, given the concentration of municipalities with agreements in the southeast region.

KEYWORDS: Sport and Leisure Policies. Intergovernmental Coordination. State Capacity.

\section{Introdução}

Este artigo se propõe discutir a política pública de lazer, Programa Federal Esporte e Lazer da Cidade - PELC, com foco na sua implementação. O lazer foi garantido como direito social pela Constituição Federal de 1988 (CF/88), em seu artigo $6^{\circ}$, junto a outros direitos como a educação, a saúde, a alimentação, o trabalho, a moradia, o transporte, a segurança, a previdência social, a proteção à maternidade e à infância, e a assistência aos desamparados.

De acordo com Menicucci (2006), a viabilização dos direitos sociais se faz pela intervenção ativa do Estado de forma positiva por meio de políticas sociais, que são políticas públicas formuladas e implementadas para resolverem problemas públicos no campo dos direitos sociais. No campo do esporte e lazer a intervenção do Estado ainda 
se encontra incipiente, no sentido de fomentar suas práticas e torná-las mais acessíveis à população.

O PELC, programa criado em 2003, pelo então Ministério do Esporte (ME), coordenado pelo governo federal e implementado no âmbito municipal, constitui-se uma das poucas iniciativas de lazer com certo grau de institucionalidade, mas com resultados ainda tímidos, conforme estudos citados adiante. Atualmente, o PELC está vinculado à Secretaria Nacional de Esporte, Educação, Lazer e Inclusão Social (SNELIS), órgão que integra a Secretaria Especial de Esporte (que substituiu o Ministério do Esporte em 2019) e tem como objetivo proporcionar a prática de atividades físicas, culturais e de lazer para todas as faixas etárias, inclusive para pessoas com deficiência. A secretaria busca ainda estimular a convivência social, a formação de gestores e lideranças comunitárias, contribuindo para que o esporte e o lazer sejam tratados como políticas e direitos de todos (BRASIL, 2019b).

Alguns estudos sobre a política de esporte e lazer, como o de Santos et al. (2019); o de Santos; Starepravo e Hirata (2018); de Ungheri (2019); Morais (2017); Pintos (2017); Secco (2019), analisaram a capilaridade e cobertura do PELC.

Santos; Starepravo e Hirata (2018), ao analisarem o processo de descentralização do programa no período de 2003 a 2012, constataram que a adesão de mais de $10 \%$ dos municípios à proposta do PELC ocorreu em apenas quatro estados brasileiros: Acre, Rondônia, Roraima e Rio de Janeiro. Em 14 estados a adesão foi abaixo de 5\%. Esses resultados indicam que o programa foi incapaz de garantir um padrão mínimo de cobertura na sua implementação (SANTOS; STAREPRAVO; HIRATA, 2018).

Quanto aos municípios que pleitearam os editais do PELC no ano de 2013, de acordo com Santos et al. (2019), um quinto das prefeituras não atingiram a pontuação mínima de 50 pontos para participarem do programa. Somada a isto, a não adesão aos 
Editais de 2013 foi de 82,2\%. De acordo com os autores, os municípios que seriam alvos prioritários das políticas sociais foram preteridos - ao menos uma parcela deles devido às dificuldades na apresentação de propostas para participação nos Editais do PELC de 2013. A capacidade técnica é o principal critério pelo qual esses municípios são julgados, e o fato de grande parte deles não atenderem a esse critério não tem sido considerado pelo desenho do programa (SANTOS et al., 2019).

Estudo realizado por Soares e Guadanini (2018), comparando as perspectivas de municipalização dos programas PELC entre os anos de 2012 e 2017, chama a atenção para um posicionamento mais negativo, ao longo do tempo, dos convenentes em relação à continuidade do programa após a finalização do convênio. Os dados demonstram uma redução de $77 \%$ para $34 \%$ do percentual de municípios conveniados que afirmaram que o programa continuaria após o fim do convênio. Também houve aumento expressivo no número de municípios que dependeriam de novo convênio com o ME para continuação do programa, variando de $48 \%$ para $84 \%$ neste período (SOARES e GUADANINI, 2018).

Ungheri (2019) fez uma leitura ampliada do PELC e ressaltou a falta de aporte financeiro como um dos principais gargalos para continuidade do programa no âmbito local. Identifica ainda alternativas que alguns municípios têm adotado para superar a falta de recursos para o programa após conclusão do convênio com o governo federal, como realização de parcerias público privadas (PPP's), busca por emendas parlamentares, participação em projetos vinculados às leis de incentivo fiscais, estabelecimento de parcerias com Universidades, trabalho em rede e, por fim, a realização de novos convênios junto ao Ministério. 
Todavia, verifica-se um número reduzido de estudos que enfatizem a implementação do PELC a partir dos arranjos institucionais para a coordenação federal do programa e da capacidade instalada dos municípios para sua execução.

Diante disto, este estudo tem por objetivo analisar a implementação dos convênios do PELC no período de 2013 a 2017, com foco nas possibilidades de continuidade do programa na esfera municipal. Para isso, busca-se tanto descrever a estrutura normativa e organizacional do programa quanto averiguar o potencial de indução e de coordenação do governo federal em relação aos municípios implementadores, além de verificar intenções e possíveis condições de perenidade do programa nas localidades, com recorte analítico nos núcleos implementados.

O artigo se ampara no aporte teórico mais amplo da descentralização e coordenação intergovernamental, no contexto da abordagem de política pública e, para tanto, está organizado, para além da presente introdução, em um tópico destinado à metodologia; um tópico de referencial teórico, onde são abordadas as relações intergovernamentais e a coordenação das políticas públicas; um tópico de resultados contendo as diretrizes do programa, a característica dos municípios, as capacidades estatais e o potencial de indução; e o tópico destinado às considerações finais, abarcando os principais achados da pesquisa.

\section{Metodologia}

Trata-se de um estudo qualitativo, de natureza estudo de caso associado a um estudo quantitativo observacional descritivo para caracterização da população. Utilizouse como técnica de coleta de dados a pesquisa documental e dados secundários, para a análise do objeto de estudo. A análise abrangeu os 43 municípios que implementaram o PELC no período de 2013 a 2017. Trata-se de um número pequeno de municípios, em 
relação ao total do país, entretanto há que se considerar que o estudo contempla o universo dos governos locais que aderiram ao programa no período em questão.

Foi analisado o seguinte conjunto de documentos do PELC: Diretrizes (BRASIL, 2017a); Orientações Estruturantes (BRASIL, 2017b); Editais públicos para implantação (BRASIL, 2017c), Modelo do Termo de Convênio (BRASIL, 2017d); Modelo de Termo de Execução Descentralizada (BRASIL, 2017e); Modelo de Proposta de Trabalho (BRASIL, 2017f); Modelo de Declaração de Capacidade Técnica e Gerencial (BRASIL, 2017g); Modelo de Declaração de Contrapartida (BRASIL, 2017h). Todos os documentos estão disponíveis para consulta pública no site oficial da Secretaria Especial de Esporte. Além destes, foram utilizados como dados secundários informações presentes nos Relatórios de Avaliação do PELC dos núcleos que estiveram em funcionamento entre os anos de 2013 e 2017.

Para a caracterização e análise estatística dos municípios conveniados foram utilizadas variáveis sociodemográficas sendo elas: Porte populacional, Gini e IDHM. Foi também pesquisada a despesa anual empenhada pelos municípios com as funções de esporte e lazer, a partir de dados extraídos do Sistema de Informações Contábeis e Fiscais do Setor Público Brasileiro - SICONFI - site da Secretaria do Tesouro Nacional (STN). Os dados pesquisados foram tratados estatisticamente para verificar se havia correlações (e quais seriam) entre as variáveis, que poderiam servir de base para a análise de implementação e possível continuidade nas ações do PELC.

Os resultados descritivos foram obtidos utilizando as frequências e porcentagens para as variáveis categóricas e a obtenção de média e desvio-padrão para as variáveis contínuas. Para comparação de médias das variáveis relacionadas às características do município conforme a manutenção no programa, foi utilizado o teste não paramétrico de Mann-Whitney. O pressuposto de normalidade foi avaliado pelo teste de Shapiro-Wilk. 
A análise também foi estratificada pelo porte populacional $(<100.000$ versus $\geq 100.000$ habitantes). Para avaliar a associação entre o porte populacional $(<100.000$ versus $\geq 100.000$ habitantes) e a manutenção no programa foi utilizado o teste Qui-quadrado de Pearson.

A associação entre as variáveis explicativas relacionadas às características do município e a manutenção no programa foi analisada por meio de razões de chances (oddsratio - OR) e seus intervalos de 95\% de confiança (IC95\%), obtidos por regressão logística binária e representada graficamente. Como as variáveis explicativas apresentam unidades de medidas diferentes, as mesmas foram padronizadas, ou seja, convertidas em uma distribuição de média igual a 0 e um desvio padrão igual a 1, para que todas as variáveis apresentem a mesma ordem de grandeza. Para cada variável a padronização é dada pela diferença de cada observação em relação à média e dividida pelo desvio-padrão. Em relação à interpretação do $\mathrm{OR}$, se $\mathrm{OR}=1$ indica que não há associação entre ambas variáveis e se o intervalo inclui o valor de "1" significa que a associação não é estatisticamente significativa. Considerou-se um nível de significância de 5\%. Para as comparações cujo valor $\mathrm{p}$ foi menor ou igual a 0,05 indica que há diferença com significância estatística.

A análise dos documentos e dos dados estatísticos foi feita a partir de categorias de análise construídas com referência à abordagem teórica utilizada neste trabalho e aos objetivos do estudo.

\section{Relações Intergovernamentais e Coordenação das Políticas Públicas}

Os países organizados sob a forma de Federação, como é o caso do Brasil, em função das características de autonomia - ainda que em graus variados, das subunidades governamentais, precisam lançar mão de mecanismos de coordenação para colocar em prática a implementação das políticas de amplitude nacional (JACCOUD et al., 2020). 
No contexto de discussão dos arranjos de coordenação em estados federativos, e tendo em vista a perspectiva de políticas de alcance nacional, observa-se, no caso brasileiro, que a Constituição de 1988 (CF/88) transferiu uma série de competências de execução de políticas para os municípios. Entretanto, a própria Constituição também garantiu ao Governo Federal a possibilidade de iniciar legislação em quase todas as áreas de políticas públicas, de forma a manter um grau de autoridade regulatória para influir na agenda política dos governos subnacionais (ARRETCHE, 2012, p. 17).

Diante desse quadro institucional/legal, verifica-se uma tendência ao fortalecimento do governo federal no papel de coordenador de políticas e diretrizes nacionais a serem implementadas pelos municípios e estados, numa lógica de padrões mínimos de atuação vinculados a repasse de recursos com incentivos e induções, como já previa a própria CF/88 (GONÇALVES; LOTTA e BITELMAN, 2008; ALMEIDA, 2005; ARRETCHE, 2012; LOTTA, 2015). Esse movimento tem sido justificado pelo fato de que, a partir do processo de descentralização, e dada a heterogeneidade das capacidades financeiras, técnicas e institucionais dos municípios, a provisão de políticas sociais ocorre de forma desigual, e, amiúde, aquém das necessidades da população. Isso teria levado a um aumento da dependência dos municípios em relação ao Governo Federal (LOTTA e VAZ, 2015).

Arretche (2004) ressalta que embora os entes federados, no caso do Brasil, apresentem autonomia e independência nos três níveis de governo, nas áreas das políticas sociais, é fundamental que exista uma coordenação central capaz de orientar os governos locais em prol do atendimento às demandas da sociedade. No que diz respeito aos mecanismos de coordenação entre nível central e local, uma característica importante são os incentivos financeiros para indução dos governos locais a aderirem aos programas federais em cada área de atuação. Além disto, os constrangimentos 
constitucionais e legais obrigam os governos locais a seguirem uma diretriz central para a implementação das políticas sociais (MACHADO, 2018).

Jaccoud et al. (2020) argumentam que o nível de exigência de uma coordenação varia em função dos objetivos elencados para a ação pública e do padrão de interdependência entre os níveis de governo (PETERS, 2004). Peters (2004) distingue quatro níveis possíveis de coordenação, com exigências diversas do que chama de capital político. O primeiro nível, identificado como sendo uma coordenação negativa, busca evitar a superposição e favorecer sinergias, impactando em melhoria na alocação de recursos, mas pouco exigente em termos de coordenação da formulação. O segundo nível mobiliza uma coordenação positiva em torno de cooperação para o fornecimento de serviços sem, contudo, alterar os objetivos perseguidos autonomamente pelos níveis de governo. O terceiro nível envolve não apenas cooperação, mas também integração de esforços, implicando um estabelecimento de objetivos e metas comuns. Mais exigente de acordos políticos, tal nível engaja um processo de negociação intergovernamental permanente, bem como a atuação ativa da autoridade central. O quarto nível se refere à coordenação entre políticas, demandando um arranjo intersetorial com estratégias de colaboração entre áreas distintas de governo (JACCOUD et al., 2020, p. 114).

$\mathrm{Na}$ perspectiva da coordenação de unidades territoriais que compõem uma Federação, o federalismo cooperativo surge como uma construção política, por meio da qual são tratadas as relações entre os diversos níveis de governo em torno de agendas comuns (GRIN; ABRUCIO, 2018). Conforme os autores, por terem interesses próprios, essas unidades territoriais podem optar por vínculos intergovernamentais ou buscar maior autonomia. Desta forma, a cooperação no sistema federalista constitui-se enquanto uma negociação e uma barganha contínuas, que buscam gerar consensos em 
que se alinhem objetivos nacionais compartilhados com a autonomia subnacional (GRIN; ABRUCIO, 2018).

Conforme Grin e Abrucio (2018), diferentes vínculos intergovernamentais gestam três tipos de cooperação: a cooperação territorial (cooperação entre todos os níveis de governo por meio de seus gestores e burocratas); a cooperação em políticas públicas (no caso em que políticas públicas de alcance federativo visam promover capacidades institucionais nos municípios, a partir da implementação de arranjos cooperativos, como, por exemplo, sistemas nacionais); e a cooperação em programas.

No âmbito da política de esporte e lazer com foco na participação e inclusão social a cooperação em programas tem sido a forma mais comum de execução.

Wright (1988), citado por Grin e Abrucio (2018), argumenta que, para o caso da adesão local a programas federais, é comum se seguir três passos: “a) interesse como função de necessidade percebida vs. disponibilidade de financiamento; b) capacidade administrativa para desenvolver a candidatura e a estimada probabilidade de sucesso; c) agências federais avaliam as candidaturas, visando medir necessidades, capacidade de implementação, inovação e benefícios" (GRIN; ABRUCIO, 2018, p.106)

O desenvolvimento das capacidades estatais municipais é um desafio para a implementação das políticas públicas. Ainda mais quando se considera que o desenvolvimento dessas capacidades é condição imperativa para uma descentralização administrativa das políticas que seja menos desigual (VELOSO et al., 2011). As novas atribuições transferidas aos municípios aumentaram as exigências no sentido de um aprimoramento de sua capacidade de gestão. Abrucio e Couto (1996) concordam que existem carências no âmbito local. Os autores enfatizam "a necessidade de serem criados instrumentos que coloquem os municípios em condições minimamente 
equânimes para execução das políticas que lhes são repassadas” (ABRÚCIO; COUTO, 1996, p. 46).

Existe uma literatura voltada à relação entre descentralização de políticas e capacidades administrativas municipais, como Mello (1996); Arretche (1999), Kugelmas (1999), mas existem poucos trabalhos na literatura brasileira que investiguem as capacidades estatais municipais como fator condicionante de resultados da descentralização (VAZQUEZ, 2012).

O conceito de capacidades estatais se origina nos estudos de sociologia política e economia política, orientados pelo modelo weberiano acerca do papel do Estado no desenvolvimento econômico e social (EVANS; RUESCHEMAYER e SKOCPOL, 1985; WEBER, 1999; SKOCPOL, 1979; EVANS, 2008). Trata-se de um conceito abrangente e multidimensional que tem orientado as análises sobre a efetividade do Estado.

Inicialmente o conceito de capacidades estatais expressava a atuação racional do Estado no desenvolvimento econômico, a partir da concepção de autonomia relativa, e da necessidade de um corpo burocrático profissional e qualificado para esta atuação. Evans (1995) avança em relação ao conceito weberiano de estado insulado e destaca a relevância de uma atuação em rede, especialmente nas relações produtivas, sem abrir mão do profissionalismo burocrático e cunha o termo embedded autonomy. Com a emergência da atuação do estado de bem estar social, na produção e a distribuição de bens e serviços coletivos (educação, saúde, transporte urbano, segurança pública etc.) a ideia de capacidades estatais passa a contemplar também os múltiplos canais de participação da sociedade civil e não apenas sua dimensão administrativa burocrática. Nesta linha argumentativa, Mann (1984) associou o poder autônomo dos Estados à capacidade destes de adentrar a sociedade e, com isso, executar suas decisões políticas 
por todo o território (SOUZA, 2018; BICHIR, 2016). Este processo, que implica uma relação de cooperação entre os cidadãos e seus governos, Mann denominou de poder infraestrutural do Estado. Para Mann, o poder (e a legitimidade) do Estado contemporâneo para governar e implementar suas políticas adviria, sobretudo, desta capacidade de interagir com os cidadãos e prover os serviços sociais básicos (MANN, 2008 apud GOMIDE, 2016).

Neste sentido, as capacidades do Estado no século XXI estariam não só associadas à qualidade das burocracias públicas, mas à existência e ao funcionamento efetivo de canais que conectem o aparato político-administrativo do Estado à sociedade civil, conferindo legitimidade, arejamento e eficácia às suas ações. Estas características aumentariam a faculdade do Estado para mobilizar os atores da sociedade em torno de um projeto de desenvolvimento social e econômico (GOMIDE, 2016).

É preciso compreender que a municipalização não ocorre considerando-se somente os atributos estruturais das unidades locais de governo, como sua capacidade fiscal, administrativa e cívica (ARRETCHE, 1999). Arretche (1999, p. 112) aponta que este processo varia de acordo com requisitos institucionais postos pelas políticas a serem assumidas pelos governos locais, tais como o legado das políticas prévias, as regras constitucionais e a engenharia operacional de cada política social. No entanto, a ação política deliberada, ou seja, estratégias de indução eficientemente desenhadas para delegar a outro nível de governo a responsabilidade pela gestão destas políticas, pode compensar obstáculos à descentralização derivados daqueles fatores de natureza estrutural ou institucional (UNGHERI, 2019). Considerando-se que o PELC é um programa coordenado pelo governo federal e implementado no nível local, este estudo irá lidar com esta relação intergovernamental. 


\section{Resultados}

\section{Diretrizes do Programa Esporte e Lazer da Cidade - PELC}

O Programa Esporte e Lazer da Cidade (PELC) surgiu em 2003 como uma das ações do recém-criado Ministério do Esporte (Medida Provisória n. 103, de $1^{\text {o }}$ de janeiro de 2003) voltadas para o esporte recreativo e para o lazer. A ideia do programa aproveitou experiências já desenvolvidas em governos de esquerda no Brasil, como nas administrações de Belém e de Recife, que valorizavam a participação popular. Seu slogan era: "o lazer vai tomar conta da sua cidade... sua cidade vai tomar conta do lazer!” (BRASIL, 2016).

Recém-criado, o PELC passa a ser uma das principais políticas da nova Secretaria Nacional de Desenvolvimento do Esporte Recreativo e do Lazer (SNDEL), que compunha a estrutura do Ministério do Esporte junto com outras duas, a Secretaria Nacional de Esporte Educacional (SNEED) e a Secretaria Nacional de Esporte de Alto Rendimento (SNEAR).

De início, foi proposto o desenvolvimento de 10 projetos pilotos em diferentes municípios brasileiros. O Manual de Orientações do PELC (BRASIL 2004, p. 4), explicita seus objetivos:

- Atender a crescente demanda da população brasileira por esporte recreativo e lazer;

- Articular ações voltadas para públicos diferenciados nos núcleos de esporte e lazer, de forma a privilegiar a unidade conceitual das mesmas e a perspectiva de relação intergeracional;

- Programar e ministrar cursos de gestão esportiva e de lazer nas cinco regiões brasileiras;

- Oferecer formação continuada a professores, estudantes e agentes sociais de esporte e lazer com base em uma concepção de gestão pública democrática, visando o trabalho em uma perspectiva intergeracional com crianças, adolescentes, jovens, adultos, idosos, pessoas com deficiência e pessoas com necessidades educacionais especiais;

- Fomentar a criação de conselhos municipais, gestores e fiscalizadores das ações voltadas para a implementação das políticas sociais de Esporte e Lazer, integrados por representantes da sociedade civil e do poder público local;

- Aplicar metodologia de avaliação processual às políticas públicas de esporte e de lazer; 
- Definir parâmetros para a construção de equipamentos esportivos e de lazer que atendam às características das políticas sociais de Esporte e Lazer implementadas e que respeitem a identidade esportiva e cultural local/regional;

- Fortalecer a capacidade de suficiência governamental, notadamente no nível dos poderes públicos municipais e estaduais, na estruturação e condução de suas políticas públicas de esporte e lazer;

- Viabilizar a produção e difusão do conhecimento científico e tecnológico de esporte e lazer por meio do fomento de eventos acadêmicos, publicações, estudos e pesquisas no âmbito do esporte recreativo e do lazer e da promoção da cooperação e do intercâmbio institucional, nacional e internacional, com vistas a qualificar a gestão e subsidiar a implementação de políticas públicas para esta área (BRASIL, 2004, p. 4).

Como pode ser percebido pela amplitude dos objetivos do PELC, a proposta inicial ia muito além do estabelecimento de núcleos de esporte recreativo e de lazer. Pode-se entender que o PELC buscava uma ação deliberada de indução de capacidades locais para ações de esporte e lazer em nível dos municípios (UNGHERI, 2019).

Entretanto, com o tempo, os núcleos de esporte e lazer passam a ocupar a centralidade do programa. Outras ações, como, por exemplo, a construção de equipamentos esportivos e a difusão de conhecimento científico, são gradativamente deslocadas para outros programas federais.

Neste artigo, foca-se na implementação dos núcleos de esporte recreativo e de lazer, que tem as seguintes finalidades:

Promove o desenvolvimento de atividades de esporte recreativo e de lazer para crianças, adolescentes, jovens, adultos, idosos, pessoas com deficiência e pessoas com necessidades educacionais especiais, visando garantir os direitos sociais de acesso ao esporte e ao lazer por parte da população, notadamente aquela em situação de vulnerabilidade social (BRASIL, 2004, p. $6)$.

A implementação dos núcleos ocorre por meio da celebração de Convênios entre

o Governo Federal e os Governos de Estado, Municípios, Distrito Federal e Universidades Estaduais, ou por Termos de Execução Descentralizada (TED) entre o Ministério do Esporte e Universidades Públicas Federais ou Institutos Federais de Educação, que se dão por meio do Sistema de Convênios do Governo Federal (SICONV). O acesso aos programas acontece por meio de chamamento público (edital), 
de emendas parlamentares ou proponente específico. Nos últimos anos, na maior parte dos casos, os candidatos passaram por um processo seletivo, em que é realizada uma avaliação de mérito.

O candidato deve preencher três documentos: proposta de trabalho; declaração de capacidade técnica e gerencial; e declaração de garantia da contrapartida (BRASIL, 2017c). A seleção das propostas é feita a partir de critérios técnicos que contemplam: os objetivos; a justificativa; o quadro resumo do pleito; as metas do projeto; as atividades sistemáticas; as atividades assistemáticas. Os critérios que buscam maior equidade entre os concorrentes (que priorizam municípios mais vulneráveis) só são contemplados no caso de desempate, sendo eles: (a) Índice de Desenvolvimento Humano (maior pontuação para os menores índices); b) Caracterização demográfica com prioridade aos municípios de até 300 mil habitantes; Atendimento a público diversificado (povos indígenas e comunidades tradicionais) (BRASIL, 2017c).

Santos et al. (2019) apontaram que a falta de capacidade técnica dos municípios que concorrem aos editais do programa tem sido um dos motivos da não participação de municípios mais vulnerabilizados ao PELC, seja por não atenderem aos critérios exigidos ou por nem pleitearem a seleção, e que o desenho do programa tem exacerbado essa realidade.

A partir do momento em que o convênio ou o Termo de Execução Descentralizada tornam-se vigentes, a entidade parceira do convênio passa a cumprir as exigências técnicas e pedagógicas do período, enquanto aguarda a Ordem de Início para o desenvolvimento das atividades do Programa. São previstos 180 dias de estruturação para que ocorra o efetivo início das atividades.

As ações de funcionamento do PELC visam contribuir com a construção de políticas públicas locais de esporte e lazer. Assim, define-se um período de 24 meses 
para que, com apoio estrutural/material do Governo Federal, a comunidade se aproprie das concepções do programa e, findado o período, trilhe os caminhos e as condições para o desenvolvimento continuado das ações.

A vigência total do convênio, 24 meses, é organizada da seguinte forma: 06 meses (180 dias) destinados à estruturação necessária ao desenvolvimento do Programa, 17 meses destinados ao efetivo atendimento aos beneficiados e 01 mês destinado ao encerramento/evento final (BRASIL, 2017b, p.04).

Para a formatação da proposta de trabalho, as entidades proponentes devem estabelecer os locais de implementação e desenvolvimento das atividades dos núcleos, tendo as praças, as quadras, os salões, os ginásios esportivos, os campos de futebol e os clubes sociais como possibilidade de alocação (BRASIL, 2017b).

As diretrizes do programa estabelecem o número de núcleos por porte dos municípios, da seguinte forma:

Figura 1: Relação densidade populacional x núcleos por município

\begin{tabular}{|c|c|}
\hline No de Habitantes & Núcleos \\
\hline Até 200.000 & Até 05 \\
\hline De 200.001 a 500.000 & Até 07 \\
\hline De 500.001 a 1 milhão & Até 10 \\
\hline Acima de 1 milhão & Até 15 \\
\hline
\end{tabular}

Fonte: Orientações Estruturantes - PELC (BRASIL, 2017b, p.04)

Os núcleos devem oferecer atividades sistemáticas e assistemáticas dirigidas às pessoas de todas as faixas etárias, sendo que cada núcleo deve atender 300 beneficiados. As atividades sistemáticas, voltadas para prática da cultura corporal e lúdica, devem ser ofertadas constantemente e em horários pré-definidos. Já as atividades assistemáticas são eventuais e devem focar tanto os participantes permanentes do núcleo como outros membros da comunidade. 
Desde 2014, o PELC funciona nos municípios com a seguinte composição de recursos humanos: um coordenador geral, um coordenador de núcleo, seis agentes sociais por núcleo, um coordenador pedagógico e um coordenador setorial em convênios com mais de 20 núcleos. Tais profissionais são pagos com recurso do governo federal, com exceção do coordenador geral, que é uma contrapartida do parceiro. Além disso, os encargos legais relacionados à contratação de recursos humanos também são de responsabilidades dos parceiros do Governo Federal.

Em quase duas décadas de existência, pode-se afirmar que a lógica de funcionamento do PELC teve pouca variação. Seus principais objetivos e diretrizes foram mantidos. Trata-se de uma política que propõe a formação continuada dos atores envolvidos, a valorização das especificidades dos territórios em que são implantados e sua gestão participativa, a partir das seguintes diretrizes: auto-organização comunitária; trabalho coletivo; intergeracionalidade; fomento e difusão da cultura local; respeito à diversidade; intersetorialidade; municipalização/institucionalização do setor.

Figura 2: Matrizes de Valores

\begin{tabular}{|c|c|c|c|c|c|c|}
\hline \multicolumn{7}{|c|}{ PROGRAMA ESPORTE E LAZER NA CIDADE - PELC } \\
\hline Ações & Qtde & Descrição & Valor Mensal & Encarges & $\begin{array}{c}\text { Custo RH } \\
\text { Mensal }\end{array}$ & Custo Total \\
\hline Núcleos & 1 & & & & & \\
\hline Participantes & 300 & & & & & \\
\hline $\begin{array}{c}\text { Material } \\
\text { Permanente }\end{array}$ & 1 & & & & & $\mathrm{R} \$ 8.000,00$ \\
\hline Eventos & 1 & & & & & $\mathrm{R} \$ 12.000,00$ \\
\hline Material Esportivo & 1 & Kit & & & & $\mathrm{R} \$ 7.000,00$ \\
\hline Uniformes & 1 & & & & & $R \$ 10.000,00$ \\
\hline \multirow{4}{*}{ Recursos Humanos } & 1 & $\begin{array}{l}\text { Coordenador } \\
\text { Pedagógico }\end{array}$ & R\$ $2.400,00$ & RS 480,00 & $\mathrm{R} \$ 2.880,00$ & $\mathrm{R} \$ 54.720,00$ \\
\hline & 0 & $\begin{array}{c}\text { Coordenador } \\
\text { Setorial }\end{array}$ & $\mathrm{R} \$ 0,00$ & RS 0,00 & R\$ 0,00 & R\$ 0,00 \\
\hline & 1 & $\begin{array}{l}\text { Coordenador de } \\
\text { Núcleo }\end{array}$ & $\mathrm{R} \$ 2.400,00$ & RS 480,00 & $\mathrm{R} \$ 2.880,00$ & $\mathrm{R} \$ 51.840,00$ \\
\hline & 6 & Agente Social & $\mathrm{R} \$ 5.700,00$ & RS 0,00 & $\mathrm{R} \$ 5.700,00$ & $\mathrm{R} \$ 102.600,00$ \\
\hline \multicolumn{4}{|c|}{ Sub - Total Recursos Ilumanos } & RS 960,00 & & \\
\hline Quantidade de RH & 8 & \multicolumn{4}{|c|}{ TOTAL GERAL } & $\mathrm{R} \$ 246.160,00$ \\
\hline
\end{tabular}

Fonte: Orientações Estruturantes - PELC (BRASIL, 2017b, p.05). 
Quanto aos recursos financeiros destinados pelo $\mathrm{ME}$, correspondentes à sua participação nas despesas pertinentes à execução do objeto do Convênio, existe um valor fixo por número de núcleos de execução.

\section{Caracterização dos Municípios Conveniados do PELC no Período de 2013 a 2017}

Considerando-se o período ora analisado, o relatório de avaliação (2018) informa o número de convênios PELC e Vida Saudável ${ }^{7}$ por ano no período de 2013 a 2017. Observa-se que 2015 foi o ano com o maior número de convênios firmados, 28 convênios, o que representa $61 \%$ do total do período. Em 2013, o número de convênios firmados ${ }^{8}$ com o Ministério do Esporte (ME) foi 3, em 2014 foram firmados 8 e em 2017 foram firmados 7 convênios. Os dados apontam um quadro bastante irregular de convênios firmados ao longo do tempo, o que é ainda exacerbado pelo ano de 2016, quando não houve qualquer convênio firmado (SOARES e GUADANINI, 2018).

O valor total destinado à implantação de cada núcleo, no ano de 2017, último do período ora analisado, foi de $\mathrm{R} \$ 246.160,00$, sendo que $\mathrm{R} \$ 209.160,00(84,9 \%)$ do valor repassado correspondeu a gastos com recursos humanos e, apenas $\mathrm{R} \$ 37.000,00$ destinou-se ao custeio (materiais de consumo, materiais permanentes, eventos e uniformes).

Considerando-se os 43 municípios que firmaram convênios com o $\mathrm{ME}$, no período de 2013-2017, 56\% do total ficam na região Sudeste, $23 \%$ no Nordeste, a região Sul é representada por $12 \%$, na região Norte $7 \%$ e no Centro Oeste $2 \%$ (SOARES e GUADANINI, 2018).

\footnotetext{
${ }^{7}$ Até 2013, Vida Saudável era a denominação que recebia uma das possibilidades do PELC, quando o programa era voltado para atender pessoas idosas. A partir dessa data, passa a existir de maneira independente o Programa Vida Saudável, com a manutenção de seu foco em indivíduos acima de 60 anos. Entretanto, apesar de ser considerado um programa independente é mantida a lógica conceitual do PELC.

${ }^{8}$ É importante esclarecer que cada convênio pode envolver mais do que um município. Convênios firmados com governos estaduais, por exemplo, podem prever o atendimento a um grande número de localidades.
} 
A Tabela 1 apresenta os dados descritivos das variáveis Porte Populacional, PIB, IDHM, GINI, relacionadas aos municípios que implementaram o PELC no período 2013-2017, mostrando que há uma dispersão dos dados a partir da média dos valores, em todas as variáveis analisadas (porte populacional, PIB, IDHM e GINI) o que demonstra a heterogeneidade desses municípios.

Tabela 1: Análise descritiva das variáveis sociodemográficas dos municípios conveniados com o PELC no período 2013-2017

\begin{tabular}{cccccc}
\hline & N & MINIMUM & MAXIMUM & MEAN & STD. DEVIATION \\
\hline Porte Populacional & 43 & 2726,00 & 999728,00 & 165029,2093 & 210500,92820 \\
PIB & 43 & 6407,69 & & 25178,3370 & 18385,31009 \\
IDHM & 43 & 0,54 & 0,80 & 0,7115 & 0,06716 \\
Gini & 43 & 0,39 & 0,63 & 0,5179 & 0,05586 \\
Valid N (listwise) & 43 & & & & \\
\hline
\end{tabular}

Fonte: DATASUS e IBGE (online, acesso 2019).

Especificamente em relação ao porte populacional, tal como ilustra o Gráfico 1, verifica-se que, embora o PELC tenha sido implementado em municípios de diferentes portes, apenas $25 \%$ do total dos convênios foram firmados com municípios de até 50 mil habitantes. A faixa populacional de 100 a 500 mil habitantes foi a que apresentou maior número de municípios conveniados. Ou seja, constata-se significativa variação populacional nas cidades que implementaram o programa, mas é possível afirmar que a maioria dos municípios conveniados é de médio porte, e a média populacional dos municípios é de 165 mil habitantes.

\section{Gráfico 1: Distribuição dos municípios conveniados por porte populacional}

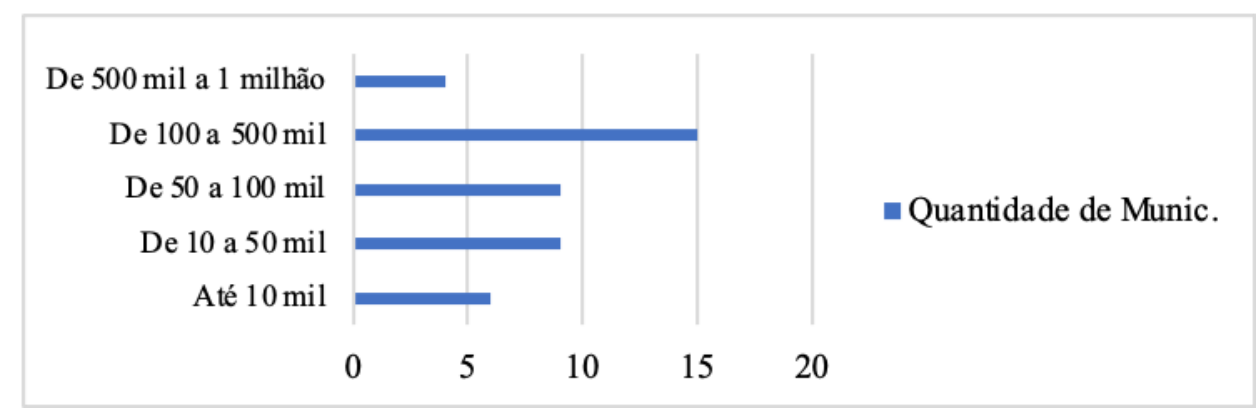

Fonte: Elaborado pelos autores 
Esse dado acompanha a tendência encontrada nos estudos de Santos; Starepravo, Hirata (2018) que afirmam que 57\% dos municípios do total de 446 convênios do PELC estão acima de 50 mil habitantes. Segundo os autores, este dado se deve ao fato de que as cidades de médio porte para cima apresentam-se com maiores chances para se conveniarem com o governo federal (SANTOS; STAREPRAVO; HIRATA, 2018), sobretudo em decorrência da capacidade técnica de alcance de elegibilidade nos editais.

\section{Capacidades Estatais dos Municípios que implementaram o PELC no Período}

\section{3-2017}

Como mencionado anteriormente, as novas atribuições transferidas aos municípios aumentaram as exigências de aprimoramento da sua capacidade de gestão para operacionalização das políticas. A heterogeneidade nas capacidades estatais municipais constitui um grande desafio para a implementação das políticas sociais, diante do objetivo de ampliação do acesso aos bens coletivos às populações em situação de desigualdades sociais e regionais (VELOSO et al., 2011).

As capacidades estatais podem ser mensuradas a partir de diferentes variáveis, neste estudo destacaremos os recursos administrativos, financeiros e normativos disponíveis para as intervenções de políticas públicas (PIERSON, 1995 apud BICHIR, 2011, p. 58).

Tais dados são importantes pois, para além da explicitação de características dos municípios que têm sido contemplados por essa política social de lazer, essas informações permitem averiguar as condições que os municípios possuem para, a partir da indução do Governo Federal via implementação de núcleos do PELC, assumirem a continuidade das ações após o fim do conveniamento. Neste estudo, foram analisados a presença de secretaria de esporte, seja exclusiva ou compartilhada e o investimento que 
os municípios fizeram na função esporte e lazer no ano de 2016, ano escolhido como um parâmetro do período analisado dos convênios.

Quanto à estrutura organizacional dos municípios analisados, todos dispunham de secretaria para o setor, sendo que a maioria das secretarias (63\%) funcionava em conjunto com outra política. Aonde há este agrupamento, o esporte geralmente compartilha secretaria com o lazer, o que mostra a afinidade entre essas duas políticas públicas (SOARES e GUADANINI, 2018).

Uma das formas de analisar o grau de institucionalidade de uma política pública é pela existência de um arcabouço normativo legal. Em relação à legislação que orienta a política de esporte lazer no âmbito local, perguntado aos municípios se a Lei Orgânica contempla o esporte,79\% dos municípios PELC responderam afirmativamente.

Um importante mecanismo de controle social, que prevê a participação da sociedade civil na formulação e implementação das políticas sociais, é a presença de conselhos deliberativos ou consultivos. No caso da política de esporte e lazer, ainda é reduzido o número de municípios brasileiros com Conselho Municipal de Esporte (CME), apenas 21\%. Situação melhor ocorre para a média dos municípios PELC onde $40 \%$ têm CME.

Sobre a participação social nas políticas públicas, Gomide (2016) destaca a importância do funcionamento de canais que conectem o aparato político-administrativo do Estado à sociedade civil, conferindo legitimidade, arejamento e eficácia às suas ações. Nesta perspectiva, os canais de participação comporiam a capacidade estatal dos municípios para gerir as políticas de esporte e lazer, e sua ausência reduz a possibilidade de mobilização de atores da sociedade em torno de um projeto para a área.

Quanto ao investimento municipal destinado às ações de esporte e lazer, dos 43 municípios conveniados com o $\mathrm{ME}$, apenas dois não dispunham de dados sobre o 
montante investido na função esporte e lazer, no ano de 2016. Do total de 41 municípios, oito investiram menos de 250 mil reais por ano na área. Desses, seis eram de pequeno porte, abaixo de 40 mil habitantes. A média dos valores investidos foi de 2.482.960,67, no entanto, tendo em vista o alto valor do desvio padrão $(2.710 .926,02)$ a mediana de 759.877,67 nos informa que pelo menos metade dos municípios investiram cerca de 750 mil reais anuais na área (STN, 2020).

O porte municipal permite inferir sobre os recursos próprios disponíveis para investimento em políticas públicas. Nesse sentido, Farina; Gouvêia; Varela (2007) afirma que os municípios de pequeno porte possuem como principal receita as transferências feitas pela União e Estados, destacando-se destas o Fundo de Participação dos Municípios (FPM), causando assim uma relação de dependência. Sobre esta dependência de repasses financeiros para composição do orçamento municipal, Bovo (2001) constatou que mais de 3000 municípios brasileiros possuíam 90\% de sua receita advinda dos fundos de transferências constitucionais.

Todavia, estudo realizado por Santos; Menezes e Lima (2019) ressalta que o grau de dependência dos municípios ao FPM pode não apresentar uma relação direta com a decisão dos gestores de investir ou não em políticas de esporte e lazer. Municípios pernambucanos com extrema dependência do FPM demonstraram investimento em políticas de esporte e lazer. Quanto ao valor empenhado na área o autor afirma que há relação direta com o fator dependência fiscal, ou seja, municípios menos dependentes tendem a investir mais nesta área.

No relatório de monitoramento do PELC (SOARES e GUADANINI, 2018) um dado importante diz respeito ao fato de que $83 \%$ dos municípios brasileiros desenvolvem ações de esporte escolar e $88 \%$ atuam no esporte como lazer, números que se elevam para $93 \%$ e $98 \%$, respectivamente, quando se trata dos municípios que 
implementaram o PELC. As ações relacionadas ao esporte de rendimento são menores nos dois grupos: $62 \%$ para os municípios do Brasil e $65 \%$ nos municípios conveniados. Esse dado é corroborado nos estudos de Santos; Starepravo e Hirata (2018) que identificaram que dos 185 municípios pernambucanos, 85\%, ou seja, 158 investiram na área de esporte e lazer. Portanto, o estudo afirma que essa é uma área de preocupação dos gestores municipais, ressaltando-se, principalmente, que não há obrigação constitucional para tal.

A despeito de não haver uma política nacional de esporte e lazer, com definições claras sobre as responsabilidades dos entes federados, parece haver uma iniciativa local na oferta de ações de esporte e lazer, em grande parte dos municípios brasileiros, amiúde, desarticuladas de quaisquer políticas federais ou estaduais, como mostra o estudo de Santos; Starepravo; Hirata (2018) sobre municípios do estado do Mato Grosso que identificaram que todos os municípios acima de 10 mil habitantes fizeram investimentos na função desporto e lazer. A despeito da inexistência de atribuições específicas da esfera local sobre a política de esporte e lazer, o estudo demonstra que os municípios têm sido ativos no investimento na área. Segundo os autores, há a efetiva descentralização das políticas públicas de esporte e de lazer no estado do Mato Grosso (SANTOS; STAREPRAVO; HIRATA, 2018).

Vale ainda destacar que a Lei Pelé, atual legislação nacional existente que regulamenta algumas ações da área, enfatiza a descentralização das ações de esporte e lazer para os níveis estaduais e especialmente locais, inclusive com repasses fiscais, sem uma menção prévia quanto à distribuição das responsabilidades das esferas de governo e à coordenação das ações intergovernamentais. 


\section{Sobre o Potencial de Indução do Governo Federal para a Continuidade do PELC}

Sabe-se que os principais mecanismos de coordenação intergovernamental para a implementação de políticas sociais se dão na forma de indução, por meio de repasse financeiro, ou por constrangimentos e orientação constitucional/legal (MACHADO, 2018).

De acordo com os diferentes níveis de coordenação apontado por Jaccoud et al. (2020), e os tipos de cooperação intergovernamental descritos por Grin e Abrucio (2018), no caso da política de esporte e lazer com ênfase na participação e inclusão social, é possível afirmar que o governo federal tem mobilizado uma coordenação de segundo nível, em torno de uma cooperação baseada em programas, para o fornecimento de serviços sem, contudo, alterar os objetivos perseguidos autonomamente pelos níveis de governo. Esse desenho de coordenação se difere do que o autor denominou terceiro nível, no qual está envolvida além da cooperação, a integração de esforços, implicando um estabelecimento de objetivos e metas comuns entre os diferentes níveis de governo. Neste caso exige-se um processo de negociação intergovernamental permanente, bem como a atuação ativa da autoridade central, algo não identificado na política de esporte e lazer.

Ainda vale acrescentar que, de acordo com a tipologia de cooperação de Grin e Abrucio (2018), diferente da cooperação por programa, expressa na proposta do PELC, a "cooperação em políticas públicas" de alcance federativo apresenta maior potencial para ampliar as capacidades institucionais nos municípios, por meio de arranjos cooperativos, tais como os que ocorrem em políticas organizadas em sistemas nacionais.

No caso do PELC, é previsto um repasse financeiro federal aos municípios que aderem ao programa, bem como diretrizes e normativas que orientam a coordenação governamental têm norteado a implementação no âmbito local. Para compreender o 
potencial de indução do governo federal para a implementação e continuidade do programa na esfera municipal, foram analisados os 46 convênios firmados com 43 municípios no período de 2013 a 2017, a partir de dados extraídos do Relatório de Avaliação do PELC.

Em 2017, apenas 34\% (13) dos conveniados afirmaram que o programa iria continuar (após o fim do conveniamento com o governo federal) e outros 25 (66\%) não souberam responder, conforme aponta o Gráfico 2. Ou seja, do total de convênios realizados, menos da metade dos municípios que implementaram o programa afirmam ter intenção de dar continuidade ao PELC.

\section{Gráfico 2: O Programa continuará vigente no município após a finalização do convênio? (PP)}

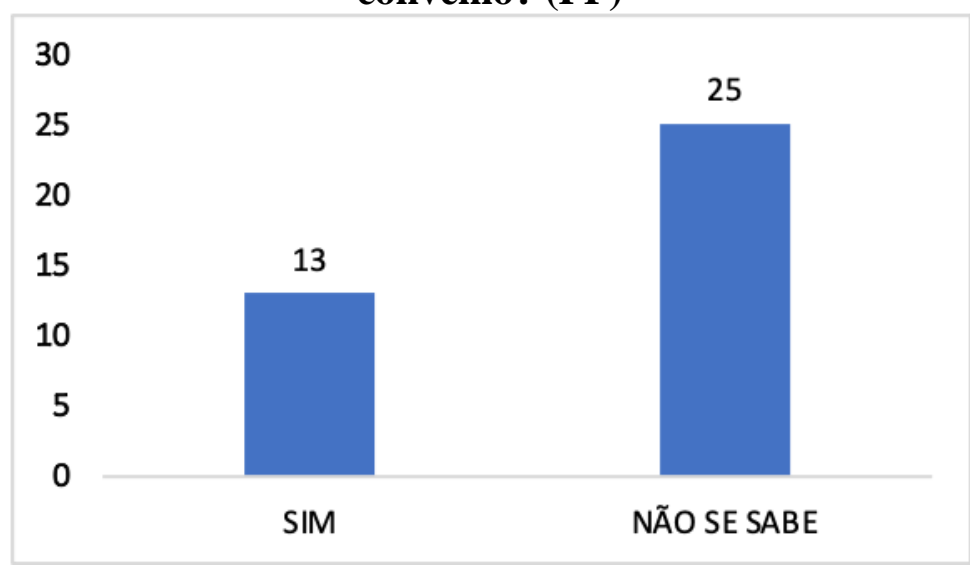

Fonte: Sistema Mimboé (BRASIL, 2019a).

Desses treze municípios, 7 são da região Sudeste, 3 da Região Norte e 3 da região Nordeste. Vale ainda destacar que, dos 19 municípios acima de 100 mil habitantes que celebraram convênio com o ME no período de 2013/17, apenas 09 afirmam que darão continuidade ao programa ao fim do convênio.

Curiosamente, 3 municípios de pequeno porte, de até 10 mil habitantes afirmam a continuidade após o fim do convênio. Este dado pode corroborar os achados de Santos; Menezes e Lima (2019) de que o porte dos municípios e sua dependência de 
repasse federal, especialmente do FPM, não estão diretamente relacionados à decisão por investir ou não em políticas de esporte e lazer.

Tabela 2: Identificação dos municípios que afirmam continuidade do programa após o término do convenio com o ME

\begin{tabular}{|c|c|c|c|}
\hline MUNICÍPIO & $\begin{array}{l}\text { REGIÃO/ } \\
\text { ESTADO }\end{array}$ & $\begin{array}{c}\text { PORTE POPULACIONAL } \\
\text { IBGE }(2010)\end{array}$ & $\begin{array}{c}\text { DESPESAS LIQUIDADAS } \\
\text { NA FUNÇÃO } \\
\text { ESPORTE/LAZER } \\
\end{array}$ \\
\hline Araguaína & Norte (TO) & 150.484 & $5.086 .497,58$ \\
\hline Belford Roxo & Sudeste (RJ) & 469.332 & $643.223,76$ \\
\hline Bonito de Minas & Sudeste (MG) & 9.673 & $420.885,39$ \\
\hline Contagem & Sudeste (MG) & 603.442 & $6.700 .747,10$ \\
\hline Maranguape & Nordeste (CE) & 113.561 & $334.448,00$ \\
\hline Monsenhor Hipólito & Nordeste (PI) & 7.391 & $25.780,31$ \\
\hline Palmas & Norte (TO) & 228.332 & $6.492 .370,55$ \\
\hline Petrolina & Nordeste (PE) & 293.962 & $133.910,00$ \\
\hline Rio Branco & Norte (AC) & 336.038 & $2.317 .208,65$ \\
\hline Sete Lagoas & Sudeste (MG) & 214.152 & $1.918 .390,60$ \\
\hline Suzano & Sudeste (SP) & 262.480 & $4.681 .313,84$ \\
\hline Valença & Sudeste (RJ) & 71.843 & $759.877,67$ \\
\hline Taquaral & Sudeste (SP) & 2.726 & $291.826,26$ \\
\hline
\end{tabular}

Fonte: Sistema Mimboé (BRASIL, 2019a).

Estudo realizado por Santos; Starepravo; Hirata (2018) que analisou no período 2003 a 2012, 446 convênios para implementação do PELC, identificou que a maioria dos municípios, em torno de $65 \%$, celebrou apenas uma vez o convênio com o governo federa, $16 \%$ celebraram duas vezes, e apenas $9,16 \%(\mathrm{n}=22)$ garantiram três convênios por município. Ou seja, se a continuidade do programa para uma parcela dos municípios depende da renovação do convênio, esses dados demonstram que esta não tem sido a solução viável, dado o número reduzido de renovação indicado pelo estudo.

Conforme aponta Tabela 3 em termos de intenção, ao serem perguntados sobre as possíveis estratégias para continuar com o programa, dos 38 municípios que responderam, 84\% (32) alegam que a continuidade do programa depende da renovação dos convênios com o Ministério.

No entanto vale ressaltar, que $24(63,2 \%)$ pretendem buscar novas fontes de recursos, $13(34,2 \%)$ irão aumentar os aportes de recursos financeiros próprios nos programas e $7(18,4 \%)$ disseram que irão recorrer a outras estratégias. Ressalta-se que 
nessa pergunta os gestores poderiam marcar mais de uma opção como resposta. Neste caso seria importante uma investigação qualitativa para se compreender com mais detalhamento de que forma os municípios levantariam novas fontes de recursos próprios para investimento no programa.

\section{Gráfico 3: Quais estratégias estão sendo construídas para dar continuidade ao programa?}

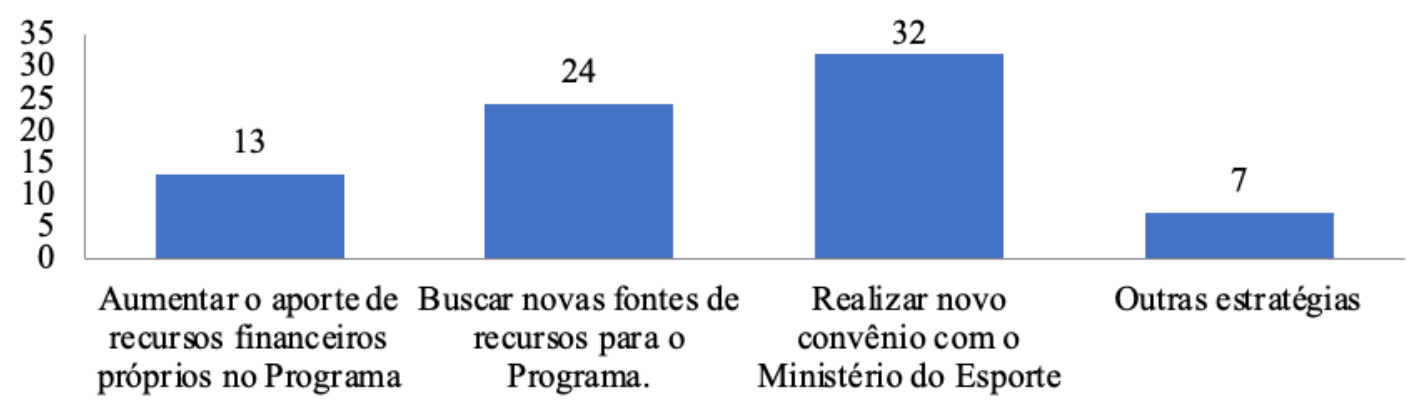

Fonte: Sistema Mimboé (BRASIL, 2019a).

Ao se analisar essa mesma questão sobre as estratégias para continuidade do PELC, considerando-se os 13 municípios que afirmaram dar continuidade ao programa após o fim do convênio, a maioria (10) apontou que pretende realizar novo convênio com o ME, 10 irão buscar novas fontes de recursos, 6 que irão aumentar os aportes de recursos financeiros próprios nos programas e 4 disseram que irão recorrer a outras estratégias. Lembrando que nessa questão o município poderia marcar mais de uma opção. Somente 3 municípios não marcaram a opção dar continuidade com a realização de um novo convênio com o Ministério do Esporte, sendo eles: Belford Roxo (SudesteRJ); Petrolina (Nordeste - PE) e Suzano (Sudeste - SP). A partir da Tabela 1 mostrada anteriormente, verifica-se que os três municípios que afirmaram dar continuidade ao programa sem buscar novo convênio com o ME estão entre os maiores em porte populacional, acima de 260 mil habitantes. 
Quanto aos resultados estatísticos que buscaram identificar associação entre as variáveis de caracterização dos municípios e a chance de continuidade do PELC, as análises demonstram que não foi observada diferença estatisticamente significante para a comparação das variáveis relacionadas às características do município conforme a manutenção ou não no programa (TABELAS 3 e 4).

\begin{tabular}{|c|c|c|c|c|}
\hline Variável & & Média ou \% & Desvio-padrão & Valor-p \\
\hline \multirow{2}{*}{ DESPESA } & Não & 2594219,00 & 1013659,00 & 0,701 \\
\hline & Sim & 2430271,00 & 748651,70 & \\
\hline \multirow{2}{*}{ POPULAÇÃO } & Não & 160776,60 & 44297,49 & 0,330 \\
\hline & Sim & 191173,70 & 50201,10 & \\
\hline \multirow{2}{*}{ PIB } & Não & 27520,31 & 3998,60 & 0,665 \\
\hline & Sim & 21631,69 & 3303,00 & \\
\hline \multirow{2}{*}{ IDHM } & Não & 0,72 & 0,01 & 0,818 \\
\hline & Sim & 0,71 & 0,02 & \\
\hline \multirow{2}{*}{ GINI } & Não & 0,51 & 0,01 & 0,050 \\
\hline & Sim & 0,55 & 0,01 & \\
\hline \multirow{2}{*}{ POPULAÇÃO $\geq 100.000$ hab. (\%) } & Não & 35,48 & 8,73 & 0,065 \\
\hline & Sim & 67,67 & 14,21 & \\
\hline
\end{tabular}

Fonte: DATASUS E IBGE (online, acesso 2019).

A Tabela 4 mostra que mesmo com a distinção por porte dos municípios (abaixo de 100 mil habitantes e acima de 100 mil habitantes) o efeito associativo permanece estatisticamente não significativo.

Tabela 4: Média das variáveis relacionadas às características do município conforme a manutenção ou não no programa

\begin{tabular}{|c|c|c|c|c|c|c|c|}
\hline & & \multicolumn{3}{|c|}{$<100,000$ hab, } & \multicolumn{3}{|c|}{$\geq 100,000 \mathrm{hab}$} \\
\hline \multicolumn{2}{|l|}{ Variável } & Média & $\begin{array}{l}\text { Desvio- } \\
\text { padrão }\end{array}$ & $\begin{array}{c}\text { Valor- } \\
\text { p }\end{array}$ & Média & $\begin{array}{l}\text { Desvio- } \\
\text { padrão }\end{array}$ & $\begin{array}{c}\text { Valor- } \\
\text { p }\end{array}$ \\
\hline \multirow{2}{*}{ DESPESA } & Não & 1125093,00 & 358449,30 & 0,173 & 5238646,00 & 2643015,00 & 0,798 \\
\hline & Sim & 374592,40 & 152509,00 & & 3458111,00 & 929182,30 & \\
\hline \multirow{2}{*}{ POPULAÇÃO } & Não & 37918,78 & 6828,21 & 0,163 & 381920,70 & 88723,50 & 0,712 \\
\hline & Sim & 22908,25 & 16375,51 & & 275306,40 & 53379,12 & \\
\hline \multirow{2}{*}{ PIB } & Não & 25305,38 & 3704,02 & 0,104 & 31507,20 & 9214,73 & 0,509 \\
\hline & Sim & 13168,48 & 4839,63 & & 25863,30 & 3608,70 & \\
\hline IDHM & Não & 0,71 & 0,02 & 0,314 & 0,74 & 0,01 & 0,620 \\
\hline
\end{tabular}




\begin{tabular}{cccccccc}
\hline & Sim & 0,65 & 0,06 & & 0,74 & 0,01 & \\
\multirow{2}{*}{ GINI } & Não & 0,51 & 0,02 & 0,353 & 0,50 & 0,01 & 0,050 \\
& Sim & 0,54 & 0,01 & & 0,55 & 0,02 & \\
\hline
\end{tabular}

Fonte: DATASUS E IBGE (online, acesso 2019).

Outro resultado encontrado refere-se ao fato de que todos os intervalos de confiança passam pelo 1, reiterando o achado anterior de que não existe associação significativa entre as características do município e a continuidade do programa (Gráfico 4).

\section{Gráfico 4: Odds Ratio da associação entre as variáveis de interesse e a manutenção ou não no programa}

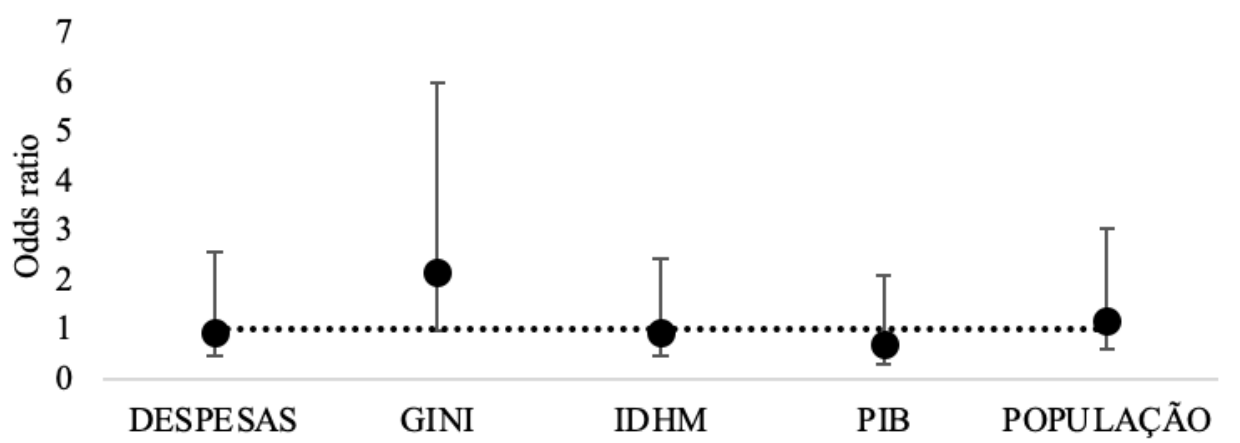

Fonte: DATASUS E IBGE (online, acesso 2019).

Embora os dados não apontem possíveis características municipais que possam estar associadas a uma maior chance de continuidade do PELC após o fím do convênio com o governo federal, percebe-se que o potencial de indução para continuidade do Programa independentemente do repasse do ME é pequeno, tendo em vista que a maioria dos municípios pretende realizar novo convênio para continuidade do projeto.

Este estudo corrobora o argumento de Wright (1988), de que, para o caso da adesão local a programas federais, a execução do programa é impactada pela disponibilidade de financiamento, situação prevista nos editais do PELC que deixam claro que a aprovação no edital não está atrelada a garantia do convênio. "Somada à capacidade administrativa para desenvolver a candidatura e a estimada probabilidade de sucesso, e à avaliação das agências federais quanto as candidaturas, visando medir 
necessidades, capacidade de implementação, inovação e benefícios", tal como ocorre em todo o processo de desenvolvimento do PELC (WRIGHT, 1988).

Enfim, para Grin e Abrucio (2018) a "capacidade de absorção" dos programas pelos municípios seguiu sendo um sério obstáculo para a grande maioria das cidades receberem apoio federal, tal como demonstra Santos et al. (2019) que ressalta a falta de capacidade técnica como um dos motivos que aumentam a inequidade dos municípios que concorrem aos editais PELC, seja pelo não atendimento aos critérios de elegibilidade seja pela não adesão à proposta.

\section{Considerações Finais}

Considerando-se o desenho do PELC, de formulação e coordenação federal e implementação municipal, foi possível identificar que o governo federal tem estimulado a adesão dos governos locais para a execução do programa, por meio de convênios com repasses financeiros e diretrizes para sua implementação.

Vale ainda destacar a amplitude das diretrizes do programa, no sentido de não apenas ofertar atividades de esporte recreativo e lazer no âmbito local, mas sobretudo, com o intuito de atuar como um parâmetro para a construção e gestão de equipamentos públicos de esporte e lazer. Destaca-se o propósito de fomentar a participação social na política por meio do estímulo à criação de conselhos municipais, a realização de formação continuada no sentido de ampliar a concepção de lazer, elemento importante para potencializar a institucionalidade da política, e por fim, fortalecer a capacidade instalada dos governos locais na estruturação e condução da política de esporte e lazer. Na prática, o programa tem se concentrado na estruturação dos núcleos e oferta de ações de esporte e lazer. 
A despeito de ser o programa mais robusto e de maior perenidade da SNELIS, a capilaridade do PELC ainda é baixa, bem como a sua cobertura, além de não atender a equidade regional, dada a concentração de municípios conveniados na região sudeste. Embora a maioria dos municípios disponha de relativa capacidade instalada para a implementação de políticas de esporte e lazer, dimensão avaliada pela presença de órgãos que respondem pela política (seja em formato de pasta única ou compartilhada), pela existência de legislação que regulamenta a área e, sobretudo, pelo investimento da esfera local em ações de esporte e lazer na quase totalidade dos municípios brasileiros, constata-se que o governo federal não alcança a meta indutória de adesão ao programa e continuidade após a conclusão dos convênios com os municípios.

As diretrizes que almejam o avanço na institucionalidade do programa não têm sido exitosas. Obviamente a forma pontual de repasse financeiro dificulta a efetividade do mecanismo indutório para continuidade das ações pelos municípios. Apesar de a maioria dos municípios analisados investirem na área, constata-se que pelo menos a metade deles investiram valores incipientes na política. Independente do porte populacional dos municípios e do investimento na área de esporte e lazer, a chance de continuidade do PELC não se altera no conjunto de municípios analisados. Ou seja, dada a baixa institucionalidade do programa, as motivações de natureza particular aos municípios tornam-se relevantes e devem ser melhor investigadas sobre a adesão ou não dos municípios ao PELC.

Deve-se indagar sobre a necessidade de redesenhar o programa em função da heterogeneidade dos municípios, considerando-se o porte e capacidade de financiamento, seja em relação ao custo final do programa, ou quanto aos critérios de elegibilidade dos municípios a fim de tornar o acesso aos editais mais equânime. 
Ademais, existe uma condição estrutural da política que não favorece uma coordenação de política pública entre os entes federados, no sentido de potencializar as capacidades locais e criar sinergias para o fortalecimento da área como direito social. Este fato advém, sobretudo, de que a coordenação federal na área dá-se prioritariamente por meio de programas e projetos em detrimento da presença de arranjos institucionais que promovam a cooperação e negociação entre os níveis de governo.

\section{REFERÊNCIAS}

ABRUCIO, F.L.; COUTO, C.G. A redefinição do papel do estado no âmbito local. São Paulo em perspectiva, v.10, n. 3, 1996.

ALMEIDA, F. D. M. Competências na Constituição de 1988. São Paulo: Editora Atlas, 2005.

ARRETCHE, M. Democracia, federalismo e centralização no Brasil. Rio de Janeiro: Editora FGV/Editora Fiocruz, 2012.

Federalismo e políticas sociais no Brasil: problemas de coordenação e autonomia. São Paulo em perspectiva, v. 18, n. 2, p. 17-26, 2004.

Políticas Sociais no Brasil: descentralização em um Estado federativo. Revista Brasileira de Ciências Sociais, v. 14, n. 40, p. 111-141, 1999.

BICHIR, R. M. A emergência e a consolidação de programas de transferência de renda no Brasil, na Argentina e na África do Sul. Capacidades estatais em países emergentes. O Brasil em perspectiva comparada. Editores: Alexandre de Ávila Gomide; Renato Raul Boschi. Instituto de Pesquisa Econômica Aplicada (IPEA). Ministério do Planejamento, Orçamento e Gestão. Rio de Janeiro. Disponível em: https://www.ipea.gov.br. 2016, p. 325 a 359.

Mecanismos federais de coordenação de políticas sociais e capacidades institucionais locais: o caso do Programa Bolsa Família. Tese de Doutorado. Rio de Janeiro: Universidade do Estado do Rio de Janeiro, 2011.

BOVO, J. M. Gastos sociais dos municípios e desequilíbrio financeiro. Revista de Administração Pública, v. 35, n. 1, p. 93-117, 2001.

BRASIL. Constituição (1988). Constituição da República Federativa do Brasil, 1988. Brasília: Senado Federal, 1988.

ME. Manual de Orientação - Programa Esporte e Lazer da Cidade. Brasília: ME, 30p. Impresso, 2004. 
MS. DATASUS Tecnologia da Informação a Serviço do SUS. 2019. Disponível em: https://tabnet.datasus.gov.br/cgi/ibge/censo/cnv/ginibr.def. Acesso em: $30 \mathrm{dez}$.

2016.

ME. Programa Esporte e Lazer da Cidade - PELC. Diretrizes. Brasília, ME - SNELIS / DFPE. Esporte e Lazer da Cidade - PELC. Diretrizes, 2017a. Disponível em: https://arquivo.esporte.gov.br/arquivos/snelis/2017/edital_02_2017_diretriz_PELC.pdf. Acesso em: 20 mar. 2020.

BRASIL. ME - SNELIS / DFPE. Esporte e Lazer da Cidade - PELC. Orientações Estruturantes, 2017b. Disponível em: https://arquivo.esporte.gov.br/arquivos/snelis/2017/edital_02_2017_orientacoes_estrutu rantesPELC.pdf . Acesso em: 20 mar. 2020.

- ME - SNELIS / DFPE. Esporte e Lazer da Cidade - PELC. Edital de chamada pública $\mathrm{n}^{\text {o }}$ 2, 2017c. Disponível em: https://arquivo.esporte.gov.br/arquivos/snelis/2017/edital_02_2017_PELC.pdf. Acesso em: 20 mar. 2020.

$\begin{array}{cccc} & \text { ME - SNELIS / DFPE. Esporte e Lazer da Cidade - PELC. Modelo Termo } \\ \text { Ce } & \text { Convênio, } & \text { 2017d. } & \text { Disponível }\end{array}$ https://arquivo.esporte.gov.br/arquivos/snelis/2017/edital_02_2017_MinutadoTermode ConvenioPELC.pdf. Acesso em: 20 mar. 2020.

ME - SNELIS / DFPE. Esporte e Lazer da Cidade - PELC. Modelo Termo de Execução Descentralizada, 2017e. Disponível em: https://arquivo.esporte.gov.br/arquivos/snelis/2017/edital_02_2017_MinutadoTermode ExecuoDescentralizada.pdf. Acesso em: 20 mar. 2020.

ME - SNELIS / DFPE. Esporte e Lazer da Cidade - PELC. Modelo de Proposta de Trabalho, 2017f. Disponível em: https://arquivo.esporte.gov.br/index.php?option=com_content $\&$ view $=$ article $\& i d=50018$ Acesso em: 20 mar. 2020.

ME - SNELIS / DFPE. Esporte e Lazer da Cidade - PELC. Modelo de Declaração de Capacidade Técnica e Gerencial, 2017g. Disponível em: https://arquivo.esporte.gov.br/index.php?option=com_content \&view=article $\& i d=50018$ Acesso em: 20 mar. 2020.

ME - SNELIS / DFPE. Esporte e Lazer da Cidade - PELC. Modelo de Declaração de Contrapartida, 2017h. Disponível em: https://arquivo.esporte.gov.br/index.php?option=com_content\&view=article \&id=50018 Acesso em: 20 mar. 2020.

ME - MIMBOÉ: Sistema de monitoramento e avaliação de políticas sociais de esporte e lazer. Brasília, 2019a. 
ME. SEE - SNELIS, 2019b. Disponível em:

https://arquivo.esporte.gov.br/index.php/contato/57-ministerio-doesporte/institucional/snelis/84-snelis2. Acesso em: $30 \mathrm{dez} .2019$.

EVANS, P. B. In Search of the 21st Century Developmental State. Working Paper $\mathrm{n}^{\mathrm{o}}$.4. University of Sussex, 2008.

. Embedded autonomy. Princeton: Princeton University Press, 1995.

.; RUESCHEMEYER, D.; SKOCPOL, T. Bringing the state back in. Cambridge, England: Cambridge University Press, 1985.

FARINA, M. C.; GOUVÊA, M. A.; VARELA, P. S., Transferências Constitucionais e Receitas Tributárias Versus Desempenho Econômico e Social de Alguns Municípios do Estado de São Paulo. In: SEMINÁRIOS EM ADMINISTRAÇÃO FEA-USP. Anais... São Paulo, 2007.

GOMIDE, A. A. Capacidades estatais para políticas públicas em países emergentes: (des) vantagens comparativas do Brasil. In (GOMIDE; BOSCHI). Capacidades Estatais em Países Emergentes - o Brasil em perspectiva comparada Brasília: IPEA, 2016. p.15-47.

GONCALVES, R.; LOTTA, G.; BITELMAN, M. A coordenação federativa de políticas públicas duas décadas após a Constituição Federal de 88. ENCONTRO NACIONAL DE ADMINISTRAÇÃO PÚBLICA E GOVERNANÇA. Salvador. Anais... Salvador: ENAPG, 2008.

GRIN, E.J.; ABRUCIO, F. L. Quando nem todas as rotas de cooperação intergovernamental levam ao mesmo caminho: arranjos federativos no Brasil para promover capacidades estatais municipais. Rev. Serv. Público, Brasília 69, edição especial, Repensando o Estado Brasileiro. 2018, p. 85-122 dez.

IBGE. Cidades. Disponível em: http://cidades.ibge.gov.br. Acesso em: 30 dez, 2019.

JACCOUD, L.; MESQUITA, A. C.; CRISTINA, E.; LICIO, J.; LEANDRO, G. Implementação e coordenação intergovernamental na Política Nacional de Assistência Social. In: JACCOUD, Luciana (org.). Coordenação e relações intergovernamentais nas políticas sociais brasileiras. Brasília: IPEA, 2020, p. 113-145.

KUGELMAS, E.; SOLA, L. Recentralização/Descentralização: dinâmica do regime federativo no Brasil dos anos 90. Tempo Social. Revista de Sociologia da USP, v.11, n. 2, p. 63-83, 1999.

LOTTA, G. S. Burocracia e implementação de políticas de saúde. Rio de Janeiro: Editora Fiocruz, 2015.

.; VAZ, J. C. Arranjos Institucionais de Políticas Públicas: aprendizados a partir de casos do Brasil. Revista do Serviço Público, v. 66, n. 2, p. 171-194, 2015.

MACHADO, J. Federalismo e políticas sociais: conexões a partir da Teoria da Agência. Revista do Serviço Público, v.69, n. 1, p. 57-84, 2018. 
MANN, M. The autonomous power of the state: Its origins, mechanisms and results. European Journal of Sociology/Archives Européennes De Sociologie/ Europäisches Archiv Für Soziologie, v. 25, n. 2, p. 185-213, 1984.

MELLO, Marcus A. Crise federativa, guerra fiscal e "hobbesianismo municipal": efeitos perversos da descentralização? São Paulo em Perspectiva, v.10, n. 3, p.11-20, 1996.

MENICUCCI, T. Políticas Públicas de Lazer. Questões analíticas e desafios políticos. In: H. F. Isayama \& M. A., Linhales (org.). Sobre Lazer e Política: maneiras de ver, maneiras de fazer. Belo Horizonte: UFMG, 2006, p. 136-164.

MORAIS, A. F. S. A. Avaliação do Programa Esporte e Lazer da Cidade no convênio de Recife. 2017. Tese (Doutorado). Universidade Federal de Minas Gerais, Belo Horizonte, 2017.

PIERSON, P. Fragmented Welfare States: Federal Institutions and the Development of Social Policy. Governance: An International Journal of Policy and Administration, v. 8, n.4, p. 449-478, 1995.

PETERS, B. Guy. Governance and public bureaucracy: new forms of democracy or new forms of control? Asia Pacific Journal of Public Administration, v. 26, n. 1, 2004, p. 3-15.

PINTOS, A. E. Análise da experiência em Monitoramento e Avaliação de Políticas Públicas do Programa Esporte e Lazer da Cidade - PELC. 2017. Dissertação (Mestrado). Universidade de Brasília, Brasília, 2017.

SANTOS, E. S.; MENEZES, V. G.; LIMA, E. W. G. Investimento na função desporto e lazer (FDL) dos municípios de Pernambuco no ano de 2013 por níveis de dependência do Fundo de Participação dos Municípios (FPM). Revista Brasileira de Ciências do Esporte, v. 41, n. 1, p. 34-40, 2019.

; STAREPRAVO, F.A.; MENEZES, V.G. de; ESDRAS, H. R. de M. Municípios e propostas vulneráveis: uma análise do edital 2013 do Programa Esporte e Lazer da Cidade (PELC). Pensar a Prática, Goiânia, v.22, 2019.

; STAREPRAVO, F. A.; HIRATA, E. Perfil das Prefeituras que Descentralizaram o PELC de 2003 a 2012. Licere, v. 21, n. 1, 2018, p. 71-88. DOI: http://doi.org/10.35699/1981-3171.2018.1768.

SECCO, E. B. O Programa Esporte e Lazer da Cidade (PELC) e a promoção do lazer: um estudo de caso no Centro Esportivo do Jardim Lavínia no município de São Bernardo do Campo. 2019. Dissertação (Mestrado). Universidade de São Paulo, São Paulo, 2019.

SKOCPOL, T. Estados e revoluções sociais: uma análise comparativa da França, Rússia e China. Cambridge University Press, 1979. 
SOARES M. M.; GUADANINI A. S. Resultados de Monitoramento e Avaliação do Programa Esporte e Lazer da Cidade (PELC) e Vida Saudável (VS). Licere, v. 21, n. 4, p. 379-404, 2018. DOI: http://doi.org/10.35699/1981-3171.2018.1946.

SOUZA, Celina. Federalismo e capacidades estatais: o papel do estado-membro na política de assistência social. In: PIRES, Roberto; LOTTA, Gabriela; Vanessa Elias de Oliveira. Instituto de Pesquisa Econômica Aplicada (IPEA)/Escola Nacional de Administração Pública (ENAP). Ministério do Planejamento, Desenvolvimento e Gestão. Brasília, 2018, p. 269 a 297.

STN. 2020. Siconfi. Disponível em: http://siconfi.tesouro.gov.br/siconfi/pages/public/declaracao/declaracao_list.jsf. Acesso em: 09 abr. 2020.

UNGHERI, B. O. Políticas Sociais de Esporte e Lazer: institucionalização e municipalização no contexto do Programa Esporte e Lazer da Cidade. Licere, v. 22, n. 2, p. 647-648, 2019.

VAZQUEZ, Daniel A. A influência das capacidades municipais nos resultados das políticas de educação e saúde. In: ENCONTRO ANUAL DA ANPOCS, 36, 2012, Caxambu. Anais... Caxambu: Anpocs., 2012.

VELOSO, J. F. A.; MONASTERIO, L. M.; VIEIRA, R. S.; MIRANDA, R. B. Gestão municipal no Brasil: um retrato das prefeituras. Brasília: Ipea, 2011.

WEBER, M. Economia e sociedade. Vol. 2: Fundamentos da sociologia. Brasília: Ed. UnB, 1999.

WRIGHT, D. S. Understanding Intergovernmental Relations. Pacific Grove: Brooks/Cole Publishing Company, 1988.

\section{Endereço dos(as) Autores(as):}

Luciana Assis Costa

Endereço eletrônico: lucianaassis.ufmg@gmail.com

Luciano Pereira da Silva

Endereço eletrônico: lpereira45@hotmai.com

Daniete Fernandes Rocha

Endereço eletrônico: daniet.rocha@gmail.com

Natascha Stephanie Nunes Abade

Endereço eletrônico: natascha_abade@yahoo.com.br

Brisa de Assis Pereira

Endereço eletrônico: brisadeassis@ hotmai.com

Marcus Peixoto de Oliveira

Endereço eletrônico: po.marcus@gmail.com 